\title{
Population Pharmacokinetics of Meropenem in Critically Ill Korean Patients and Effects of Extracorporeal Membrane Oxygenation
}

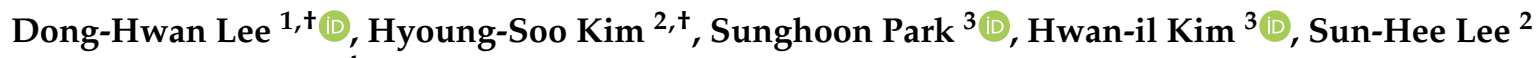 \\ and Yong-Kyun Kim ${ }^{4, *}$ \\ 1 Department of Clinical Pharmacology, Hallym University Sacred Heart Hospital, \\ Hallym University College of Medicine, Anyang 14066, Korea; dhlee97@hallym.or.kr \\ 2 Department of Thoracic and Cardiovascular Surgery, Hallym University Sacred Heart Hospital, \\ Hallym University College of Medicine, Anyang 14066, Korea; cskhs99@hallym.or.kr (H.-S.K.); \\ shlee1425@hallym.or.kr (S.-H.L.) \\ 3 Division of Pulmonary, Allergy and Critical Care Medicine, Department of Internal Medicine, \\ Hallym University Sacred Heart Hospital, Hallym University College of Medicine, Anyang 14066, Korea; \\ f2000tj@hallym.or.kr (S.P.); hwanil@hallym.or.kr (H.-i.K.) \\ 4 Division of Infectious Diseases, Department of Internal Medicine, Hallym University Sacred Heart Hospital, \\ Hallym University College of Medicine, Anyang 14066, Korea \\ * Correspondence: amoureuxyk@hallym.or.kr; Tel.: +82-31-380-3724; Fax: +82-31-380-1555 \\ + D.-H.L. and H.-S.K. contributed equally to this work as co-first authors.
}

Citation: Lee, D.-H.; Kim, H.-S.; Park, S.; Kim, H.-i.; Lee, S.-H.; Kim, Y.-K. Population Pharmacokinetics of Meropenem in Critically Ill Korean Patients and Effects of Extracorporeal Membrane Oxygenation.

Pharmaceutics 2021, 13, 1861. https://doi.org/10.3390/ pharmaceutics13111861

\section{Academic Editors: Jonás}

Samuel Pérez-Blanco and José Martínez Lanao

Received: 30 September 2021 Accepted: 1 November 2021 Published: 4 November 2021

Publisher's Note: MDPI stays neutral with regard to jurisdictional claims in published maps and institutional affiliations.

Copyright: () 2021 by the authors. Licensee MDPI, Basel, Switzerland. This article is an open access article distributed under the terms and conditions of the Creative Commons Attribution (CC BY) license (https:// creativecommons.org/licenses/by/ $4.0 /)$.
Abstract: Limited studies have investigated population pharmacokinetic (PK) models and optimal dosage regimens of meropenem for critically ill adult patients using the probability of target attainment, including patients receiving extracorporeal membrane oxygenation (ECMO). A population PK analysis was conducted using non-linear mixed-effect modeling. Monte Carlo simulation was used to determine for how long the free drug concentration was above the minimum inhibitory concentration (MIC) at steady state conditions in patients with various degrees of renal function. Meropenem PK in critically ill patients was described using a two-compartment model, in which glomerular filtration rate was identified as a covariate for clearance. ECMO did not affect meropenem PK. The simulation results showed that the current meropenem dosing regimen would be sufficient for attaining $40 \% \mathrm{f}_{>\mathrm{MIC}}$ for Pseudomonas aeruginosa at MIC $\leq 4 \mathrm{mg} / \mathrm{L}$. Prolonged infusion over $3 \mathrm{~h}$ or a high-dosage regimen of $2 \mathrm{~g} / 8 \mathrm{~h}$ was needed for MIC $>2 \mathrm{mg} / \mathrm{L}$ or in patients with augmented renal clearance, for a target of $100 \% f \mathrm{~T}_{>\text {MIC }}$ or $100 \% f \mathrm{~T}_{>4 \mathrm{XMIC}}$. Our study suggests that clinicians should consider prolonged infusion or a high-dosage regimen of meropenem, particularly when treating critically ill patients with augmented renal clearance or those infected with pathogens with decreased in vitro susceptibility, regardless of ECMO support.

Keywords: meropenem; population pharmacokinetics; critically ill patient; adult; extracorporeal membrane oxygenation; Monte Carlo simulation

\section{Introduction}

Antibiotic treatment is a major factor in determining the survival of critically ill patients diagnosed with sepsis. Altered pharmacokinetics (PK) in these patients is a major obstacle for clinicians when determining an adequate antibiotic dosage regimen [1]. The "third spacing" phenomenon caused by vasodilation and capillary leakage in sepsis patients increases the volume of distribution and lowers the drugs' serum concentration, especially for hydrophilic antimicrobials [1,2], such as $\beta$-lactams and aminoglycoside, that are more affected by pathophysiological changes than lipophilic drugs [3].

Meropenem, a carbapenem $\beta$-lactam agent with a wide spectrum of activity against Gram-positive and Gram-negative pathogens, is used for the treatment of severe infections 
caused by multidrug-resistant organisms in intensive care unit (ICU) patients, including those on extracorporeal membrane oxygenation (ECMO) support [4-7]. A large heterogeneity was observed in the volume of distribution (over two-fold) in sepsis patients admitted to the ICU and receiving meropenem [3]. ECMO may further complicate PK changes in volume of distribution and clearance [8,9], which highlights the need for optimizing meropenem dosage in adult patients on ECMO. However, the effects of ECMO on the optimal dosage for meropenem have not been elucidated. Limited studies have performed population PK modelling and evaluated the pharmacodynamic (PD) alterations associated with ECMO [10-12]. Moreover, knowledge regarding the PK/PD profile of meropenem during ECMO and its clinical relevance for different ethnicities is also limited.

This study aimed to construct a population PK model for meropenem in critically ill Korean adult patients, including those receiving ECMO, to explore the effects of ECMO on meropenem PK. Moreover, we investigated optimal dosage regimens of meropenem by assessing the probability of PK/PD target attainment for various regimens using Monte Carlo simulations.

\section{Methods}

\subsection{Patients}

This prospective study was conducted in Hallym University Sacred Heart Hospital (840-bed university-affiliated tertiary referral hospital), Anyang, South Korea, from September 2020 to April 2021. Clinical indications for meropenem included: empirical management of sepsis from unknown source, nosocomial infections, and prophylactic administration for patients undergoing ECMO. Patients with a history of $\beta$-lactam allergy or a positive skin test result for meropenem were excluded. The demographic factors between the ECMO and the non-ECMO groups were compared. If meeting normality, the $t$-test was performed; otherwise, the Wilcoxon rank-sum test was used.

\subsection{ECMO Apparatus}

The ECMO system used was the Permanent Life Support (PLS) System (MAQUET, Rastatt, Germany), which consists of a broad range of HLS Cannulae and the Rotaflow Console. The PLS Set includes the PLS-i Oxygenator. A total of $1 \mathrm{~L}$ of plasma solution or normal saline was infused into the circuit, and the total circuit volume was 500-600 mL.

\subsection{Study Design}

Patients were able to participate at any time after the initiation of meropenem administration. Patients received 500 or $1000 \mathrm{mg}$ of meropenem for 30 min every 8 or $12 \mathrm{~h}$ via intravenous (IV) infusion. Five blood samples were collected after the first dose following patients' enrollment, and two samples were collected at steady state after four or five consecutive doses. The planned sampling times for model development were as follows: (1) immediately before dosing, (2) $0.5,1,4$, and $8 \mathrm{~h}$ after the start of the infusion for the $8 \mathrm{~h}$ interval, and (3) $0,0.5,1,6$, and $12 \mathrm{~h}$ after the start of the infusion for the $12 \mathrm{~h}$ interval. Samples were collected before (trough level) and $30 \mathrm{~min}$ after (peak level) the fourth or fifth dosage, for model validation.

\subsection{Meropenem Assay}

Meropenem plasma concentrations were analyzed using high-performance liquid chromatography (HPLC)-tandem mass spectrometry (MS). The HPLC system consisted of a prominence LC-20A System (Shimadzu, Japan) and a Gemini $\mathrm{C}_{18}$ column (Kinetex; Phenomenex, Torrance, CA, USA). The MS detection was conducted using a hybrid triple quadrupole/Linear Ion trap mass spectrometer (API4000 QTRAP; SCIEX, Framingham, MA, USA). Briefly, a $100 \mu \mathrm{L}$ aliquot of plasma sample was pipetted into a centrifuge tube. Next, $100 \mu \mathrm{L}$ of acetonitrile containing an internal standard $(20 \mu \mathrm{g} / \mathrm{mL}$, ceftazidime) was added to the tube and then vortexed for $1 \mathrm{~min}$. After centrifugation at 12,000 rpm for $2 \mathrm{~min}$, the supernatant was transferred to another centrifuge tube, and $100 \mu \mathrm{L}$ of $0.1 \%$ 
formic acid was added to the tube. An aliquot of $10 \mu \mathrm{L}$ was injected into the LC-MS/MS system. The lower limit of quantitation was $0.2 \mathrm{mg} / \mathrm{L}$. The assay results were linear over a range from 0.2 to $200 \mathrm{mg} / \mathrm{L}\left(\mathrm{R}^{2}=0.99\right)$. Intraday precision and accuracy of the validation concentration range $(0.5,5$, and $50 \mathrm{mg} / \mathrm{L})$ analyzed using standard samples were $2.98-3.92 \%$ and $96.53-110.07 \%$, respectively. Interday precision and accuracy of the validation concentration range $(0.5,5$, and $50 \mathrm{mg} / \mathrm{L})$ analyzed using standard samples for 3 days were $0.5-2.7 \%$ and $89.9-100.0 \%$, respectively.

\subsection{Population PK Analysis}

Population PK modeling was implemented using the Nonlinear-mixed effects modelling software (NONMEM ${ }^{\circledR}$ 7.5, ICON Development Solutions, Elliot City, MD, USA). The first-order conditional estimation with interaction (FOCEI) method was used to estimate measured (fixed) and unexplained (random) effect parameters. FOCEI allows the interaction between the inter-individual variability (IIV, $\eta$ ) of PK parameters and the residual variability (RV) of measured concentrations. RV was caused by inter-individual variability, measurement error, assay error, and model misspecification. One-, two-, and three-compartment structural models were investigated using the PK model library in NONMEM. All PK processes were assumed to follow first-order kinetics rather than zeroorder infusion. The PK parameter was defined as $\theta_{i}=\theta \times \exp \left(\eta_{i}\right)$, where $\theta$ is the typical value of the PK parameter, $\theta_{i}$ is an individual PK parameter, and $\eta_{i}$ is a random effect associated with IIV, which is assumed to have a normal distribution with a mean of 0 and a variance of $\omega^{2}$. Proportional, additive, or combined proportional and additive error models were tested for $\mathrm{RV}$, which was assumed to have a normal distribution with a mean of 0 and a variance of $\sigma^{2}$. A power parameter was tested to allow for nonlinear heteroscedastic variances [13].

Models were evaluated and selected based on NONMEM objective function values (OFVs), precision of parameter estimates (relative standard errors), shrinkage of IIV, and diagnostic goodness-of-fit plots. In a log-likelihood ratio test, a decrease in the OFV $(\triangle \mathrm{OFV})$ between two nested models, having 1 degree of freedom greater than 3.84 or 2 degrees of freedom greater than 5.99, was considered statistically significant at $p<0.05$ for model improvement. Diagnostic plots included the following four plots: conditional weighted residuals (CWRES) vs. time, CWRES vs. model-predicted population concentration (PRED), observation vs. PRED, and observation vs. model-predicted individual concentration.

Perl-speaks-NONMEM software (PSN, version 5.2.6, available online: https:/ / uupharmacometrics.github.io/PsN, accessed on 17 June 2021)) was used for searching covariates, evaluating a model with visual predictive check and conducting nonparametric bootstrap to obtain 95\% confidence intervals (CIs). To search significant covariates for the PK parameters, stepwise forward inclusion and backward exclusion processes were conducted. Statistical significance was set at $p<0.01(\triangle \mathrm{OFV}<-6.635$ for 1 degree of freedom) for inclusion and $p<0.001$ ( $\triangle \mathrm{OFV}>10.83$ for 1 degree of freedom) for exclusion. A significant covariate should have both statistical significance and clinical relevance. The tested covariates for structural PK parameters were age, sex, height, weight, body surface area (BSA), serum albumin level, serum protein level, serum creatinine level, serum cystatin $C$ level, primary diagnosis, comorbidity, renal function, ECMO type (veno-arterial (VA) or veno-venous (VV)), and ECMO flow rate. The renal function was calculated by applying Chronic Kidney Disease Epidemiology Collaboration (CKD-EPI), modified CKD-EPI, Modification of Diet in Renal Disease (MDRD), modified MDRD, and Cockcroft-Gault (CG) formulations to determine the total clearance (CL). The modified CKD-EPI and MDRD estimates were adjusted using individual BSA values, where BSA was calculated by applying the Du Bois formula. Visual predictive check with prediction and variability correction (VPC $\mathrm{PVC}_{\text {) }}$ ) was performed using PSN by comparing the final PK model with the measured plasma concentrations with $80 \%$ prediction intervals from 1000 virtual datasets. Nonparametric bootstrapping was performed to investigate the stability of the final PK model. The median and 95\% confidence interval for the estimates 
of bootstrap samples $(n=2000)$ were generated to evaluate the parameter estimates of the final PK model. R software (version 4.0.4, available online: www.rproject.org, accessed on 11 March 2021) was used for the postprocessing of model output and visualization.

The individual PK parameters between ECMO and non-ECMO groups were compared. If meeting normality, an independent $t$-test was used; otherwise, Wilcoxon rank-sum test was used.

\subsection{Assessment of Prediction Performance}

The predictive performance of the final PK model was assessed visually using the relative prediction error ( $\mathrm{rPE}$ ) vs. the observed concentration plot and numerically using the relative bias (rBias) for accuracy and the relative root-mean-square error (rRMSE) for precision.

$$
\begin{gathered}
r P E=\frac{C_{P}-C_{O}}{C_{O}} \\
r B i a s=100 \% \frac{1}{N} \sum_{i} \frac{C_{P}-C_{O}}{C_{O}} \\
\text { rRMSE }=100 \% \sqrt{\frac{1}{N} \sum_{i} \frac{\left(C_{P}-C_{O}\right)^{2}}{C_{O}^{2}}}
\end{gathered}
$$

where $C_{O}$ indicates the observed concentrations, and $C_{P} v$ the predicted concentrations.

\subsection{PD Target Attainment}

Four Monte Carlo simulations were implemented. The first simulation was conducted to explore the adequacy of the recommended dosage regimen (for a creatinine clearance $\left[\mathrm{CL}_{\mathrm{CR}}\right]>50 \mathrm{~mL} / \mathrm{min}, 1 \mathrm{~g}$ every $8 \mathrm{~h}$ by i.v. infusion; for a $\mathrm{CL}_{\mathrm{CR}}$ of $26-50 \mathrm{~mL} / \mathrm{min}, 1 \mathrm{~g}$ every $12 \mathrm{~h}$ by i.v. infusion; for a $\mathrm{CL}_{\mathrm{CR}}$ of $10-25 \mathrm{~mL} / \mathrm{min}, 500 \mathrm{mg}$ every $12 \mathrm{~h}$ by i.v. infusion; for a $\mathrm{CL}_{\mathrm{CR}}<10 \mathrm{~mL} / \mathrm{min}, 500 \mathrm{mg}$ every $24 \mathrm{~h}$ i.v. infusion) when treating adult patients infected with Pseudomonas aeruginosa (P. aeruginosa). A total of 10,000 individual PK parameters were generated for virtual patients assuming a log-normal distribution for each parameter with the typical parameter values and the IIV of the final PK model. The selected covariate, glomerular filtration rate (eGFR) estimated using the CKD-EPI equation, was generated assuming a log-normal distribution within the range of 0 to $130 \mathrm{~mL} / \mathrm{min}$. Patients were treated empirically without knowing the pathogen, while minimum inhibitory concentration (MIC) values were generated using the clinical breakpoint distribution of MICs set by the European Committee on Antimicrobial Susceptibility Testing. They were randomly assigned to the 10,000 virtual patients. The steady-state concentration-time profiles of the virtual patients were generated using the simulated individual PK parameters and the recommended dosage regimen.

The antimicrobial activity of meropenem is related to the cumulative percentage of a $24 \mathrm{~h}$ period during which the free drug (unbound to protein, $f$ ) concentration exceeds the MIC for a pathogen, in steady-state condition $\left(f \mathrm{~T}_{>\mathrm{MIC}}\right)$. The parameter $f$ was fixed at $98 \%$. The tested treatment targets were $40 \% f \mathrm{~T}_{>\mathrm{MIC}}, 100 \% f \mathrm{~T}_{>\mathrm{MIC}}$, and $100 \% f \mathrm{~T}_{>4 \mathrm{XMIC}}$. A dosage strategy was considered adequate if the probability of target attainment (PTA) was greater than or equal to $90 \%$. The PTAs for treatment target were compared for various combinations of renal function, MICs, and dosage regimen of the patients.

The second, third, and fourth simulations were conducted to determine the optimal dosage regimen for $40 \% f \mathrm{~T}_{>\mathrm{MIC}}, 100 \% f \mathrm{~T}_{>\mathrm{MIC}}$, and $100 \% f \mathrm{~T}_{>4 \mathrm{XMIC}}$ as treatment targets, respectively. A total of 1000 individual PK parameters were generated for virtual patients assuming a log-normal distribution for each parameter, whereas the covariate was generated by applying a uniform distribution within the range 0 to $170 \mathrm{~mL} / \mathrm{min}$. The patients were divided into the six renal function groups $\left(0<\mathrm{CL}_{\mathrm{CR}} \leq 10,10<\mathrm{CL}_{\mathrm{CR}} \leq 25\right.$, $25<\mathrm{CL}_{\mathrm{CR}} \leq 50,50<\mathrm{CL}_{\mathrm{CR}} \leq 90,90<\mathrm{CL}_{\mathrm{CR}} \leq 130$, and $\left.130<\mathrm{CL}_{\mathrm{CR}} \leq 170 \mathrm{~mL} / \mathrm{min}\right)$. Steadystate concentration-time profiles of the 1000 virtual patients were generated for various 
combinations of the three doses $(0.5,1$, and $2 \mathrm{~g})$, two dosing intervals ( 8 and $12 \mathrm{~h})$, four infusion times $(0.5,1,2$, and $3 \mathrm{~h})$, and $\operatorname{MICs}(0.060,0.125,0.25,0.5,1,2,4,8$, and $16 \mathrm{mg} / \mathrm{L})$.

\section{Results}

\subsection{Patient Characteristics}

The demographic and clinical characteristics of the 26 patients are described in Table 1. Eight adult patients received ECMO (veno-arterial (VA) ECMO, $n=7$; veno-venous (VV) $\mathrm{ECMO}, n=1)$. One of the 18 patients in the non-ECMO group and one of the eight patients in the ECMO group received continuous renal replacement therapy. Patients on ECMO support were younger (median age, interquartile range [IQR]; 64.0 [56.3-66.5] vs. 72.0 [66.0-80.3] days; $p=0.0167$ ). The severity scores, including the APACHE II (median [IQR]; 12 [10-14] vs. 10 [7-14]; $p=0.0321$ ) and SOFA scores (median [IQR]; 9.50 [8.00-12.5] vs. 5.00 [3.00-7.75]; $p=0.0051$, were significantly higher in patients in the ECMO group compared to those in the non-ECMO group.

Table 1. Patients' characteristics (median (IQR)).

\begin{tabular}{|c|c|c|c|}
\hline Parameter & ECMO $(n=8)$ & Non-ECMO $(n=18)$ & $p$-Value \\
\hline ECMO type & VA $7 / \mathrm{VV} 1$ & & \\
\hline CRRT & Yes $3 /$ No 5 & Yes $1 /$ No 17 & \\
\hline Sex & male 4 / female 4 & male 14 /female 4 & \\
\hline Age (year) & $64.0(56.3-66.5)$ & $72.0(66.0-80.3)$ & $0.0167^{\mathrm{c}}$ \\
\hline Height $(\mathrm{cm})$ & $162(153-169)$ & $165(156-170)$ & $0.6544^{\mathrm{d}}$ \\
\hline Weight (kg) & $63.5(61.9-66.3)$ & $54.4(50.5-64.5)$ & $0.1731^{\mathrm{d}}$ \\
\hline Body surface area $\left(\mathrm{m}^{2}\right)$ & $1.67(1.61-1.75)$ & $1.63(1.51-1.72)$ & $0.5074^{\mathrm{c}}$ \\
\hline ICU duration (days) & $25.0(6.00-43.5)$ & $6.50(4.00-17.8)$ & $0.1249^{d}$ \\
\hline APACHE II & $21.0(19.5-22.5)$ & $16.0(12.0-18.0)$ & $0.0321^{\mathrm{c}}$ \\
\hline SOFA & $9.50(8.00-12.5)$ & $5.00(3.00-7.75)$ & $0.0051^{\mathrm{c}}$ \\
\hline BUN (mg/dL) & $26.9(22.0-33.0)$ & $22.6(10.8-46.6)$ & $0.8675^{\mathrm{d}}$ \\
\hline Scr $(\mathrm{mg} / \mathrm{dL})$ & $0.820(0.518-1.15)$ & $0.615(0.458-1.43)$ & $0.9557^{\mathrm{d}}$ \\
\hline Cystatin C (mg/dL) & $1.48(1.43-1.90)$ & $1.34(0.985-1.86)$ & $0.5411^{\mathrm{c}}$ \\
\hline Albumin (g/dL) & $3.00(2.83-3.20)$ & $2.55(2.30-2.98)$ & $0.0364^{\mathrm{c}}$ \\
\hline Protein $(\mathrm{g} / \mathrm{dL})$ & $5.15(4.88-5.75)$ & $5.05(4.70-5.75)$ & $0.5448^{\mathrm{d}}$ \\
\hline $\mathrm{CL}_{\mathrm{CR}}$, Cockcroft-Gault (mL/min) & $76.9(59.5-105)$ & $73.4(32.7-92.6)$ & $0.4367^{\mathrm{d}}$ \\
\hline GFR, MDRD $\left(\mathrm{mL} / \mathrm{min} / 1.73 \mathrm{~m}^{2}\right)$ & $86.9(67.1-132)$ & $111(47.5-160)$ & $0.9119^{c}$ \\
\hline GFR, modified MDRD $(\mathrm{mL} / \mathrm{min})^{b}$ & $88.7(67.0-115)$ & $95.1(45.0-153)$ & $0.8676^{\mathrm{d}}$ \\
\hline GFR, CKD-EPI $\left(\mathrm{mL} / \mathrm{min} / 1.73 \mathrm{~m}^{2}\right)$ & $87.7(70.0-105)$ & $91.6(45.6-103)$ & $0.7145^{\mathrm{c}}$ \\
\hline GFR, modified CKD-EPI $(\mathrm{mL} / \mathrm{min})^{b}$ & $82.4(70.0-94.9)$ & $77.7(43.6-97.0)$ & $0.5883^{c}$ \\
\hline
\end{tabular}

IQR, interquartile range; ECMO, extracorporeal membrane oxygenation; VA, veno-arterial; VV, veno-venous; CRRT, continuous renal replacement therapy; APACHE II, Acute Physiology and Chronic Health Evaluation; SOFA, sequential organ failure assessment; BUN, serum blood urea nitrogen level; Scr; serum creatinine level; $\mathrm{CL}_{\mathrm{CR}}$, creatinine clearance; GFR, glomerular filtration rate; MDRD, Modification of Diet in Renal Disease; CKD-EPI, Chronic Kidney Disease Epidemiology Collaboration. ${ }^{b}$ The modified MDRD and CKD-EPI equations adjusted to individual BSA are GFR $(\mathrm{mL} / \mathrm{min})=$ GFR $\left(\right.$ MDRD or CKD-EPI) $\times\left(\mathrm{BSA} / 1.73 \mathrm{~m}^{2}\right)$. ${ }^{\mathrm{c}}$ Independent $t$-test. ${ }^{\mathrm{d}}$ Wilcoxon rank-sum test.

\subsection{Population PK Analysis}

A total of 125 samples were used to develop a population PK model, and 44 samples to validate the final model. The concentration-time profile of meropenem was best described by a two-compartment model. The NONMEM OFVs for one-, two-, and three-compartment models were $689.840,6540.693$, and 640.694, respectively.

The structural parameters for the two-compartment model were total clearance (CL), central volume of distribution $\left(\mathrm{V}_{\mathrm{C}}\right)$, peripheral volume of distribution $\left(\mathrm{V}_{\mathrm{P}}\right)$, and intercompartmental clearance $(Q)$ between $V_{C}$ and $V_{P}$. The inter-individual variability (IIV) was estimated for CL, V1, and V2 (Table 2). In the final PK model (OFV 611.402), GFR was estimated using the CKD-EPI equation and identified as a statistically significant covariate of CL. The IIV for CL was reduced from 55.2\% to $31.4 \%$ after the covariate were included. ECMO therapy did not affect the meropenem PK in this study. 
Table 2. Population PK parameter estimates for meropenem.

\begin{tabular}{|c|c|c|c|}
\hline Parameter & Estimates & $\begin{array}{c}\text { RSE (\%) } \\
\text { [Shrinkage }(\%)]\end{array}$ & Bootstrap Median $(95 \% \mathrm{CI})$ \\
\hline \multicolumn{4}{|l|}{ Structural model } \\
\hline \multicolumn{4}{|c|}{$C L=\theta_{1} \times\left(1+\theta_{2} \times(C E-91.57)\right)$} \\
\hline$\theta_{1}(\mathrm{~L} / \mathrm{h})$ & 6.37 & 7.41 & $6.32(5.42-7.23)$ \\
\hline$\theta_{2}$ & 0.00925 & 10.3 & $0.00932(0.00680-0.0110)$ \\
\hline $\mathrm{V}_{\mathrm{C}}(\mathrm{L})$ & 9.07 & 12.2 & $8.97(3.92-12.0)$ \\
\hline $\mathrm{Q}(\mathrm{L} / \mathrm{h})$ & 10.7 & 21.5 & $10.6(4.73-31.0)$ \\
\hline $\mathrm{V}_{\mathrm{P}}(\mathrm{L})$ & 7.91 & 13.6 & $8.17(5.35-11.1)$ \\
\hline \multicolumn{4}{|l|}{ Inter-individual variability } \\
\hline CL $(\%)$ & 31.4 & $15.8[3.70]$ & $29.9(18.0-38.7)$ \\
\hline $\mathrm{V}_{\mathrm{C}}(\%)$ & 43.6 & $22.5[14.7]$ & $41.0(0.000-95.4)$ \\
\hline $\mathrm{V}_{\mathrm{P}}(\%)$ & 36.6 & $21.0[41.3]$ & $34.5(0.000-55.7)$ \\
\hline \multicolumn{4}{|l|}{ Residual variability } \\
\hline Proportional error $(\%)$ & 24.6 & $29.3[24.2]$ & $24.1(10.3-41.5)$ \\
\hline Power parameter & 0.865 & 10.0 & $0.897(0.533-1.38)$ \\
\hline
\end{tabular}

ECMO, extracorporeal membrane oxygenation; RSE, relative standard error; CL, total clearance; $\theta_{1}$, typical population value for CL; $\theta_{2}$, covariate coefficient for $\mathrm{CE} ; \mathrm{V}_{\mathrm{C}}$, central volume of distribution; $\mathrm{V}_{\mathrm{P}}$, peripheral volume of distribution; $\mathrm{Q}$, inter-compartmental clearance between $\mathrm{V}_{\mathrm{C}}$ and $\mathrm{V}_{\mathrm{P}} ; \mathrm{CE}$, glomerular filtration rate estimated by $\mathrm{CKD}$-EPI equation.

The PK parameter estimates were not significantly different between the ECMO and the non-ECMO groups (Table 3). Residual error was well described using a proportional error model. The power parameter for RV reduced the relative standard error (RSE) of the IIV for CL from $27.3 \%$ to $22.5 \%$. When IIV was expressed as a standard deviation, if the RSE of IIV exceeded $25 \%$, it was not significant.

Table 3. Comparison of population PK parameter estimates between the ECMO and the non ECMO groups.

\begin{tabular}{cccc}
\hline Parameter & ECMO & non ECMO & $p$-Value \\
\hline CL & $6.34(4.84-7.92)$ & $5.05(3.43-7.37)$ & $0.5782^{\mathrm{b}}$ \\
$\mathrm{V}_{\mathrm{C}}(\mathrm{L})$ & $8.37(7.35-8.89)$ & $8.53(7.21-11.7)$ & $0.6567^{\mathrm{c}}$ \\
$\mathrm{V}_{\mathrm{P}}(\mathrm{L})$ & $8.11(7.75-8.86)$ & $8.28(6.55-8.64)$ & $0.4258^{\mathrm{b}}$ \\
$\mathrm{V}_{\mathrm{SS}}(\mathrm{L})$ & $16.2(15.6-17.9)$ & $17.2(14.7-21.0)$ & $0.6140^{\mathrm{b}}$ \\
\hline
\end{tabular}

ECMO, extracorporeal membrane oxygenation; $C L$, total clearance; $V_{C}$, central volume of distribution; $\mathrm{V}_{\mathrm{P}}$, peripheral volume of distribution; $\mathrm{V}_{\mathrm{SS}}$, steady-state volume of distribution. ${ }^{\mathrm{b}}$ Independent $t$-test. ${ }^{\mathrm{c}}$ Wilcoxon rank-sum test.

The diagnostic goodness-of-fit plots for the final PK model are depicted in Figure 1. Conditional weighted residuals (CWRES) were randomly distributed around the x-axis, indicating no systemic deviation in the structural model (Figure 1a) or in the residual error model (Figure 1b); most of them remained within \pm 2 times the normalized standard deviation. The observation values were randomly distributed around the line of identity, indicating no evidence of misspecification of the structural, IIV, or RV model (Figure 1c,d).

$\mathrm{VPC}_{\mathrm{PVC}}$ is shown in Figure 2, where most of the observations fall within the $80 \%$ prediction interval of the simulated concentrations, and the observed 10th, 50th, and 90th percentiles are overlaid with $95 \%$ CIs of the simulated 10th, 50th, and 90th percentiles. This plot suggests that the final PK model correctly explained the data and had appropriate predictive performance. The time course for individual observed, individual predicted, and population predicted concentrations is shown in Figure S1. 

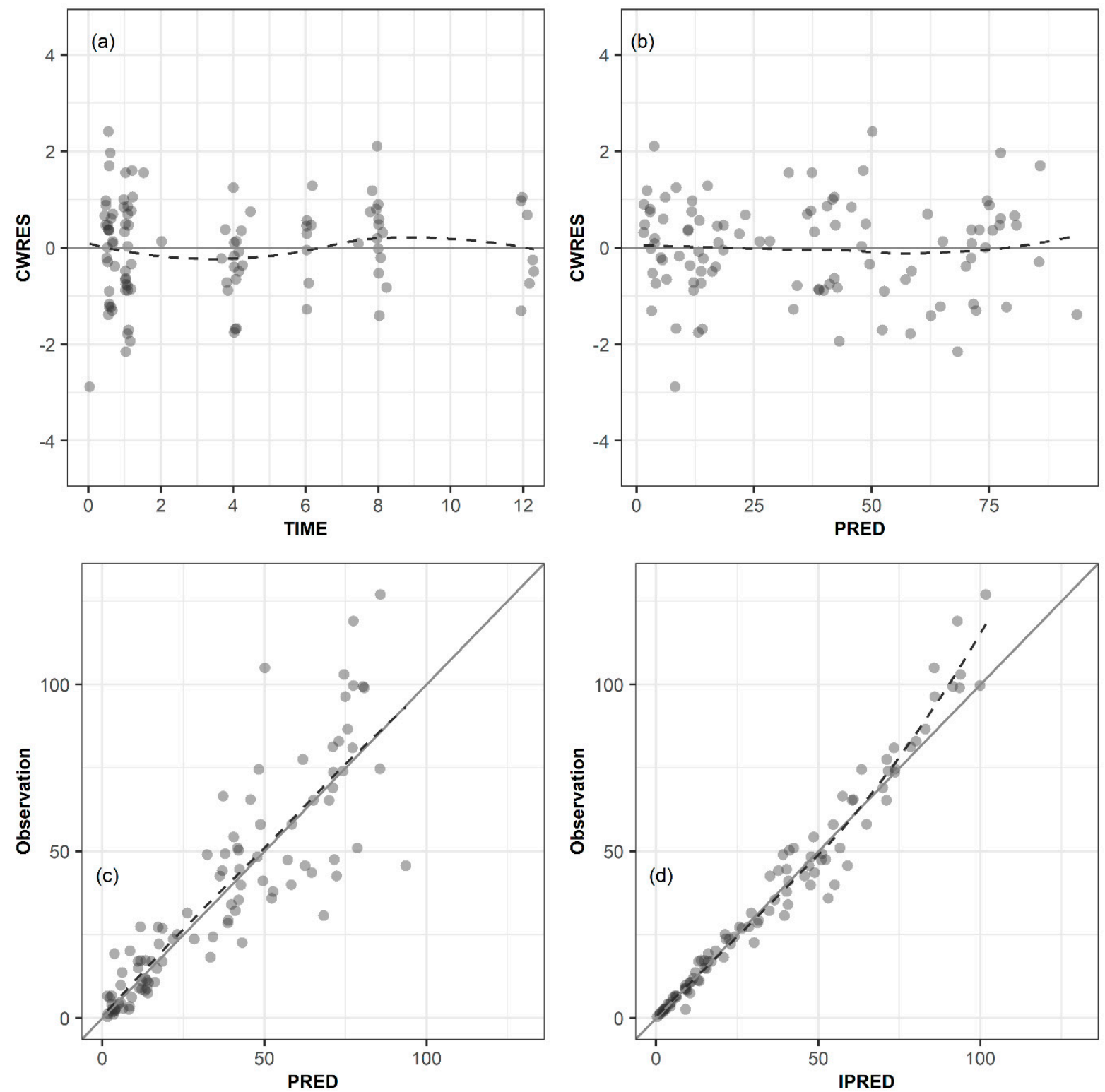

Figure 1. Goodness-of-fit plots. (a) Conditional weighted residuals (CWRES) versus time, (b) CWRES versus population predicted concentration (PRED), (c) observed concentration versus PRED, and (d) observed concentration versus individual predicted concentration. The dashed lines indicate smooth curves.

\subsection{Assessment of Prediction Performance}

Figure $\mathrm{S} 2$ displays the relative prediction error (rPE) vs. the observed concentration. As shown, most values are distributed around the $x$-axis. When the concentration exceeded $50 \mathrm{mg} / \mathrm{L}$, underprediction was observed. When all subjects were included, the relative bias (rBias) and relative root-mean-square error (rRMSE) were $17.5 \%$ and $91.5 \%$, respectively. However, when two subjects with extreme outliers were excluded, the rBias and rRMSE were $1.59 \%$ and $29.4 \%$, respectively.

\subsection{PD Target Attainment}

Figure 3 shows the PTA of empirical therapy using the current dosage regimen in the first simulation. The recommended dosage regimen achieved $90 \%$ PTA at $40 \% f \mathrm{~T}_{>\mathrm{MIC}}$ when the MIC was less than $8 \mathrm{mg} / \mathrm{L}$; however, it did not achieve $90 \%$ PTA at $100 \% f \mathrm{~T}_{>\mathrm{MIC}}$ when the MIC was greater than $0.25 \mathrm{mg} / \mathrm{L}$. If the target was $100 \% \mathrm{~T}_{>4 \mathrm{XMIC}}$, the current regimen could not reach the $90 \%$ PTA regardless of the MIC. 


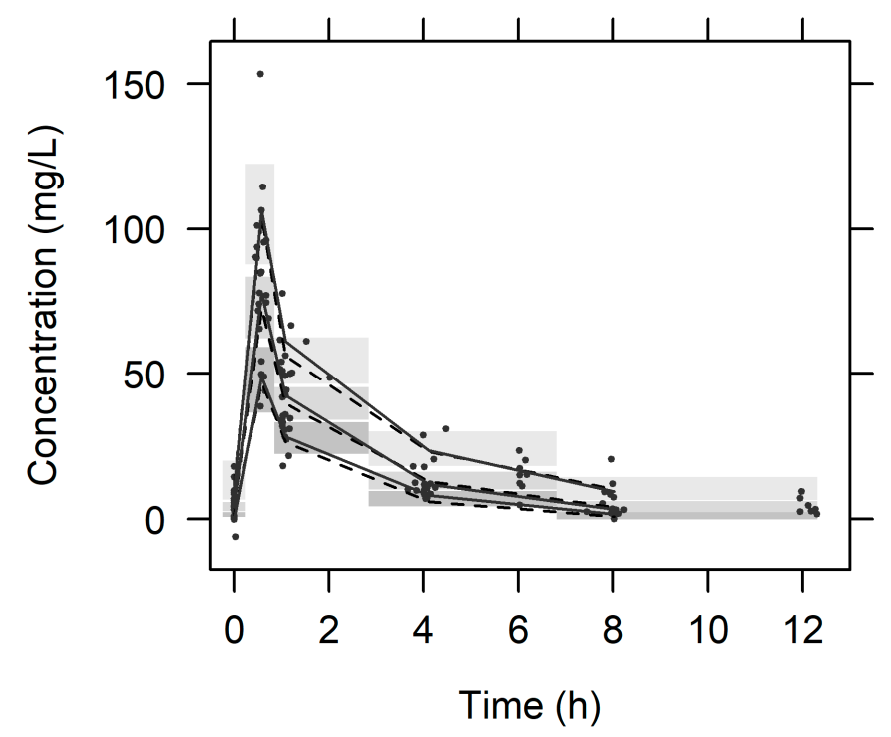

Figure 2. Visual predictive check plot. Plots from virtual concentrations of 1000 simulated datasets. Closed circles, observed serum meropenem concentrations; solid lines, the 10th, 50th, and 90th percentiles of observations; dashed lines, the 10th, 50th, and 90th percentiles of simulated serum meropenem concentrations; shaded areas, 95\% confidence intervals for each percentiles of simulated concentrations.

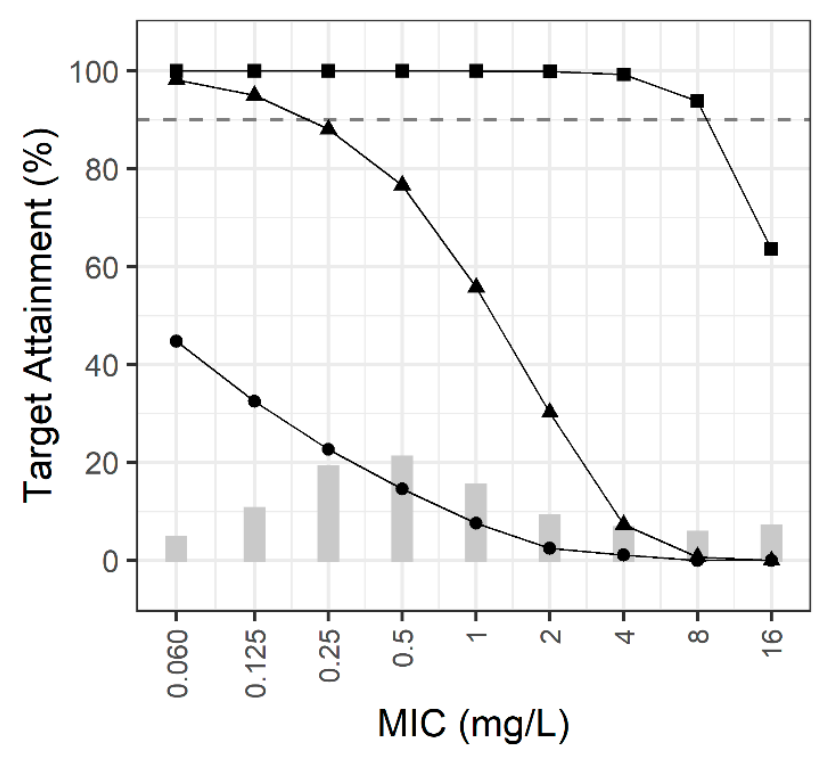

- $f T_{>M I C} \geq 40 \% \quad \Delta \quad f T_{>M I C} \geq 100 \%$ - $f T_{>4 \times M I C} \geq 100 \%$

Figure 3. Probabilities of target attainment (PTA) of empirical therapy using the current dosage regimen for patients with an eGFR of $0-130 \mathrm{~mL} / \mathrm{min} / 1.73 \mathrm{~m}^{2}$. Bars indicate the MIC distribution for P. aeruginosa.

In the second simulation, optimal dosage regimens were explored to achieve PTA $>90 \%$ at $40 \% f \mathrm{~T}_{>\text {MIC }}$ (Figure 4 ). In the case of patients with an eGFR of $26-50 \mathrm{~mL} / \mathrm{min} / 1.73 \mathrm{~m}^{2}$, a regimen of $1 \mathrm{~g}$ every $12 \mathrm{~h}$ using i.v. infusion over $30 \mathrm{~min}$ could attain a $90 \%$ PTA when the MIC was $4 \mathrm{mg} / \mathrm{L}$. However, a dosage regimen of $0.5 \mathrm{~g}$ every $12 \mathrm{~h}$ was also appropriate for patients in this study. As expected, a prolonged infusion enhanced the PTA. For patients with eGFR values of $90-130 \mathrm{~mL} / \mathrm{min} / 1.73 \mathrm{~m}^{2}$, a dosage regimen of $1 \mathrm{~g}$ every $12 \mathrm{~h}$ using i.v. infusion over $2 \mathrm{~h}$ was optimum when the MIC was $4 \mathrm{mg} / \mathrm{L}$, whereas $30 \mathrm{~min}$ or $1 \mathrm{~h}$ of infusion was not. 


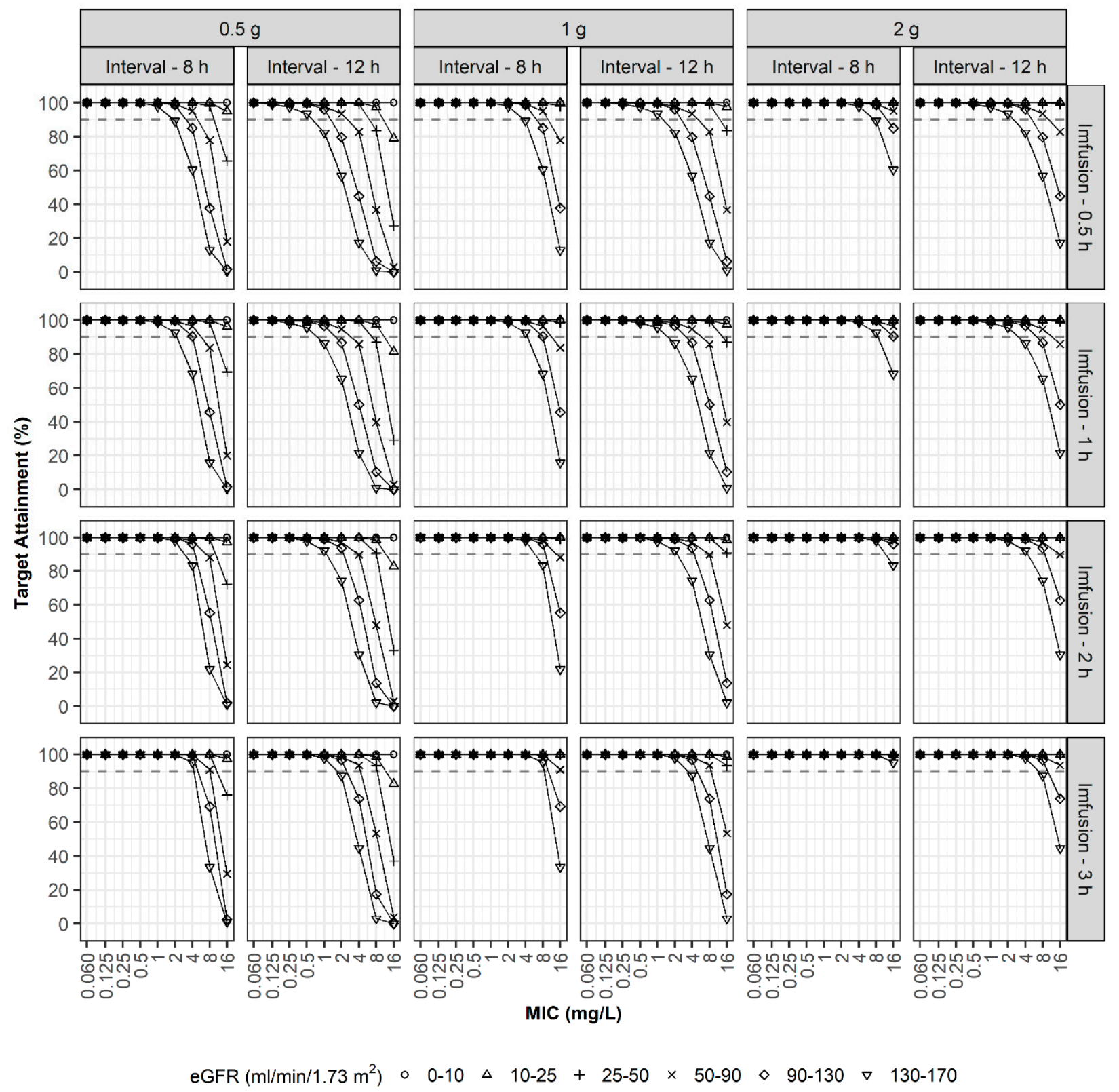

Figure 4. PTAs $\left(40 \% f \mathrm{~T}_{>\mathrm{MIC}}\right)$. Simulation results with three doses $(0.5,1$, and $2 \mathrm{~g})$, two dosing intervals (8 and $\left.12 \mathrm{~h}\right)$, four infusion times $(0.5,1,2$, and $3 \mathrm{~h})$, various degrees of renal function, and various MICs.

In the third simulation, optimal dosage regimens were explored to achieve PTA $>90 \%$ at $100 \% f \mathrm{~T}_{>\mathrm{MIC}}$ (Figure 5). In the case of patients with an eGFR of $50-90 \mathrm{~mL} / \mathrm{min} / 1.73 \mathrm{~m}^{2}$, a regimen of $1 \mathrm{~g}$ every $8 \mathrm{~h}$ using i.v. infusion over $30 \mathrm{~min}$ or prolonged infusion over $3 \mathrm{~h}$ could attain a $90 \%$ PTA when the MIC was $1 \mathrm{mg} / \mathrm{L}$ and $2 \mathrm{mg} / \mathrm{L}$, respectively. For patients with augmented renal clearance (eGFR values of $130-170 \mathrm{~mL} / \mathrm{min} / 1.73 \mathrm{~m}^{2}$ ), a regimen of $1 \mathrm{~g}$ every $8 \mathrm{~h}$ using prolonged i.v. infusion over $3 \mathrm{~h}$ was optimum only when the MIC was equal to or less than $0.25 \mathrm{mg} / \mathrm{L}$, and a high-dosage regimen of $2 \mathrm{~g}$ every $8 \mathrm{~h}$ using prolonged i.v. infusion over $3 \mathrm{~h}$ was optimum when the MIC was less than $1 \mathrm{mg} / \mathrm{L}$. 


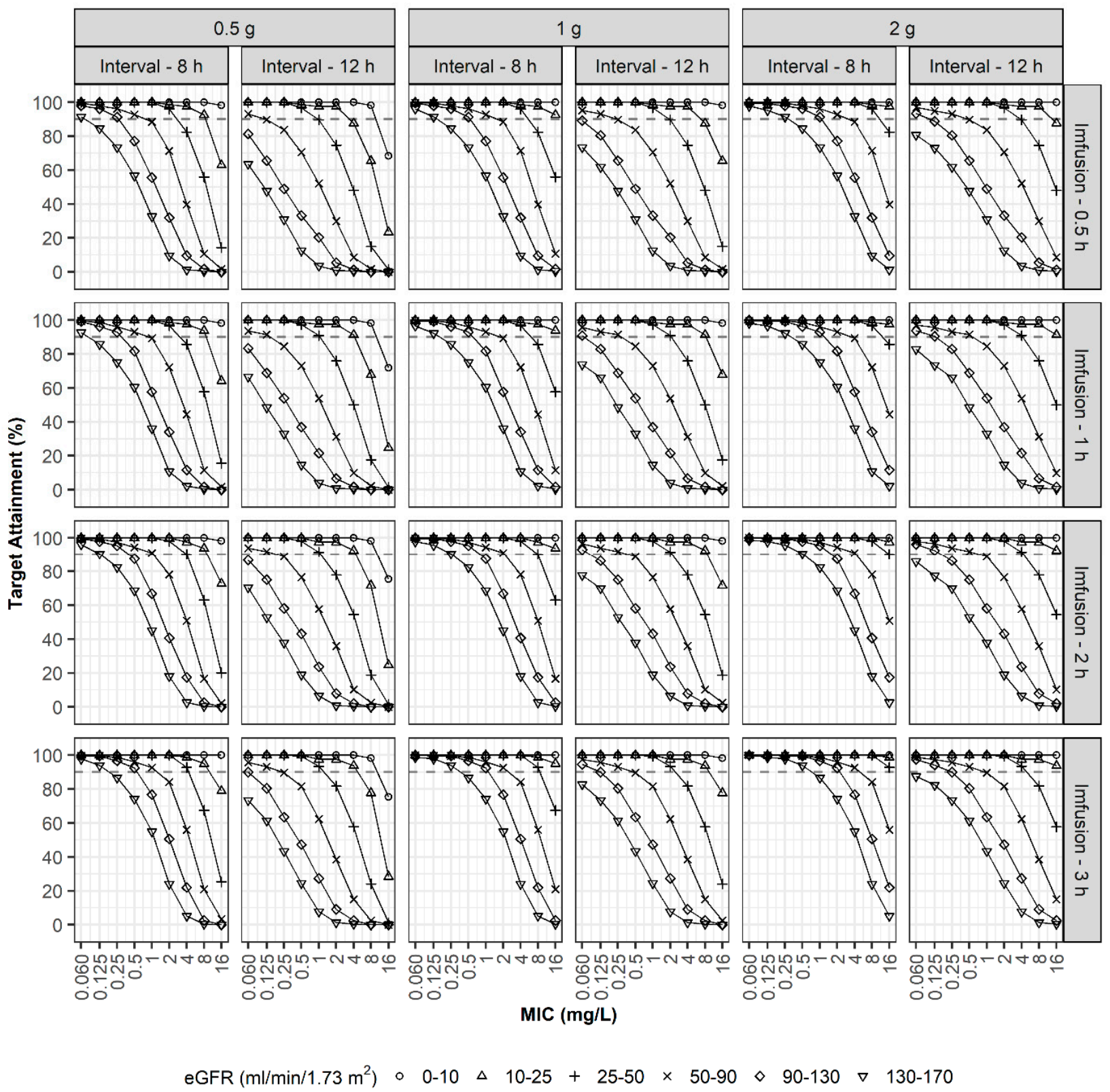

Figure 5. PTAs $\left(100 \% f \mathrm{~T}_{>\mathrm{MIC}}\right)$. Simulation results with three doses $(0.5,1$, and $2 \mathrm{~g})$, two dosing intervals $(8$ and $12 \mathrm{~h})$, four infusion times $(0.5,1,2$, and $3 \mathrm{~h})$, various degrees of renal function, and various MICs.

In the fourth simulation, optimal dosage regimens were explored to achieve PTA $>90 \%$ at $100 \% f \mathrm{~T}_{>4 \text { XMIC }}$ (Figure 6 ). In the case of patients with an eGFR of $50-90 \mathrm{~mL} / \mathrm{min} / 1.73 \mathrm{~m}^{2}$, a regimen of $1 \mathrm{~g}$ every $8 \mathrm{~h}$ using i.v. infusion over $30 \mathrm{~min}$ could attain a 90\% PTA when the MIC was $\leq 0.25 \mathrm{mg} / \mathrm{L}$, and the high-dosage regimen of $2 \mathrm{~g}$ every $8 \mathrm{~h}$ using prolonged i.v. infusion over $3 \mathrm{~h}$ could attain a $90 \%$ PTA when the MIC was $\leq 1 \mathrm{mg} / \mathrm{L}$. For patients with augmented renal clearance (eGFR values of $130-170 \mathrm{~mL} / \mathrm{min} / 1.73 \mathrm{~m}^{2}$ ), the high-dosage regimen of $2 \mathrm{~g}$ every $8 \mathrm{~h}$ using prolonged i.v. infusion over $3 \mathrm{~h}$ was optimum only when the MIC was less than $0.25 \mathrm{mg} / \mathrm{L}$. 


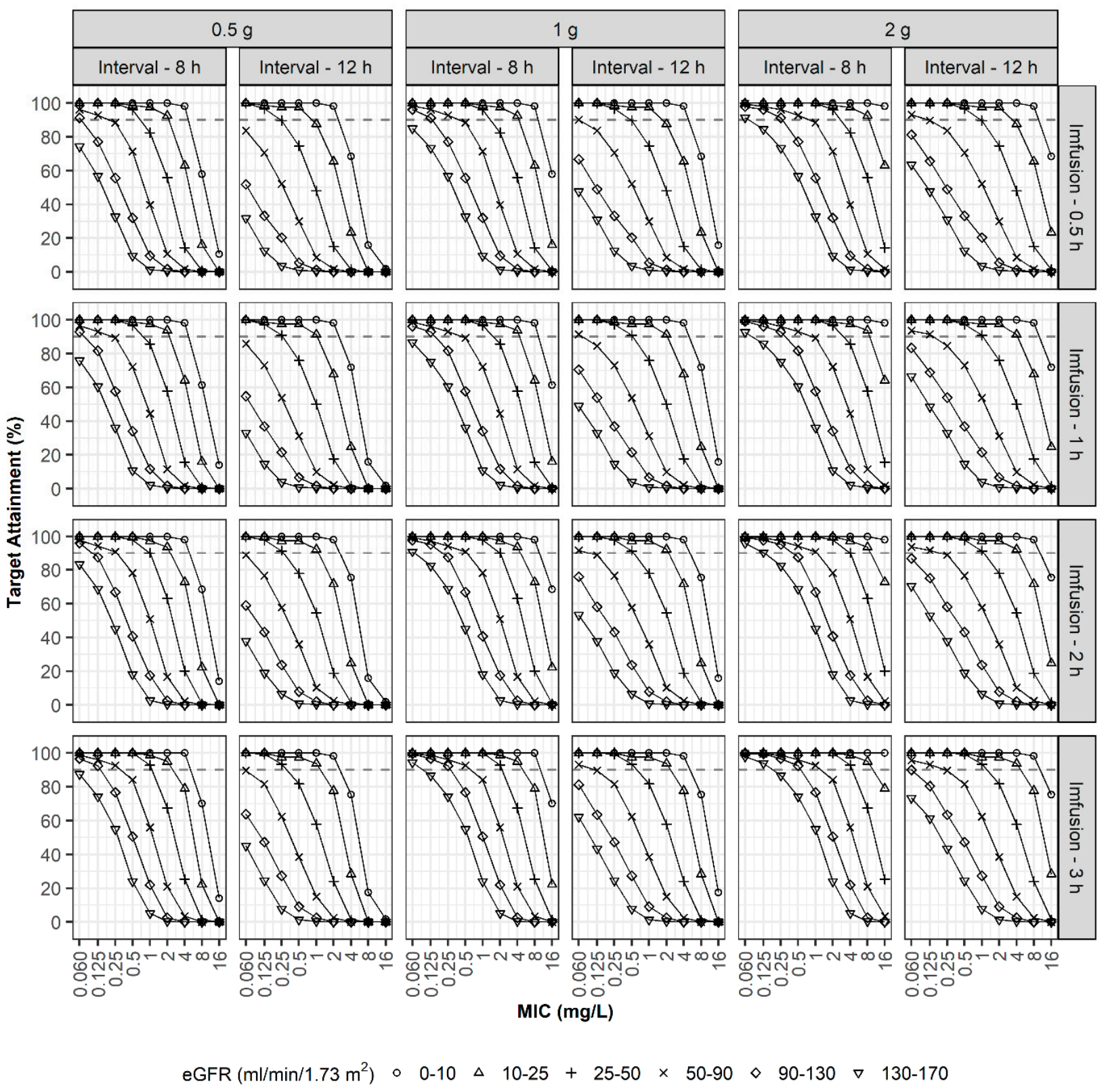

Figure 6. PTAs $\left(100 \% \mathrm{f}_{>4 \mathrm{XMIC}}\right)$. Simulation results with three doses $(0.5,1$, and $2 \mathrm{~g})$, two dosing intervals $(8 \mathrm{and} 12 \mathrm{~h})$, four infusion times $(0.5,1,2$, and $3 \mathrm{~h})$, various degrees of renal function, and various MICs.

\section{Discussion}

This study presents the PK properties of meropenem in critically ill Korean adult patients, including those undergoing ECMO. The PK of meropenem was best described by a two-compartment model, in which the glomerular filtration rate (GFR) was estimated using the CKD-EPI equation and identified as a significant covariate for CL. The final PK model demonstrated good predictive performance, while using ECMO did not affect meropenem PK. The results of Monte Carlo simulations to achieve more than $90 \%$ PTA at $40 \% f \mathrm{~T}_{>\mathrm{MIC}}$ suggest that the current dosage regimen of meropenem using i.v. infusion over $30 \mathrm{~min}$ is sufficient to treat $P$. aeruginosa at MIC $\leq 4 \mathrm{mg} / \mathrm{L}$ in the case of patients with a $\mathrm{CL}_{\mathrm{CR}}$ of $50-90 \mathrm{~mL} / \mathrm{min} / 1.73 \mathrm{~m}^{2}$. Prolonged i.v. infusion of meropenem over at least $2 \mathrm{~h}$ could attain a $90 \%$ PTA when the MIC is $4 \mathrm{mg} / \mathrm{L}$ for patients with augmented renal clearance (eGFR values of $130-170 \mathrm{~mL} / \mathrm{min} / 1.73 \mathrm{~m}^{2}$ ). However, to achieve PTA $>90 \%$ at $100 \% f \mathrm{~T}_{>\mathrm{MIC}}$ or $100 \% \mathrm{f}_{>4 \mathrm{XMIC}}$, prolonged infusion over $3 \mathrm{~h}$ or a high-dosage regimen of $2 \mathrm{~g}$ 
every $8 \mathrm{~h}$ should be considered, particularly for MIC $>2 \mathrm{mg} / \mathrm{L}$ or in patients with an eGFR of $130-170 \mathrm{~mL} / \mathrm{min} / 1.73 \mathrm{~m}^{2}$.

Prescribing an antibiotic with a narrow therapeutic range is one of the most challenging concerns in the treatment of critically ill patients with time-varying and highly variable PK. The current paucity of knowledge about PK regarding ECMO use in critically ill patients makes it more difficult to adjust dosage regimens. Regardless of ECMO support, PTA for achieving $100 \% f \mathrm{~T}_{>\mathrm{MIC}}$ and $100 \% f \mathrm{~T}_{>4 \mathrm{XMIC}}$ in the present study was low when meropenem was used following the currently recommended dosage regimen to treat even susceptible P. aeruginosa (MIC $\leq 2 \mathrm{mg} / \mathrm{L}$ ) in patients with normal renal clearance. These results are consistent with those of previous studies that performed population PK modelbased simulations in critically ill patients, including those on ECMO support [10-12]. We postulate that prolonged infusion of meropenem over $3 \mathrm{~h}$ or a high-dosage regimen of $6 \mathrm{~g} /$ day should be considered, particularly for treating critically ill patients with increased renal clearance and those infected with less susceptible pathogens, to provide appropriate meropenem concentrations to them and those on ECMO support. Real-time therapeutic drug monitoring (TDM)-guided dosing optimization of meropenem using dosing software could further help clinicians to improve clinical outcomes and reduce toxicity in critically ill patients [14-16]. Evaluating the influence of TDM of meropenem on clinical outcomes in ECMO patients is warranted, since the use of inappropriate meropenem concentrations is possible, especially when using the standard-dose regimen [17].

Regarding poor clinical outcomes associated with elevated meropenem MIC [18-20], the development of guidance for appropriate meropenem dosage optimization for empirical treatment should be considered to overcome antimicrobial resistance in the ICU [21]. High-dosage regimens of meropenem using prolonged infusion over $3 \mathrm{~h}$ could be considered for the empirical treatment in critically ill patients [22-25], which is supported by our simulation results revealing the low PTA of empirical therapy using the current dosing regimen. Previous studies have reported the positive impact of prolonged meropenem infusion on clinical outcomes such as hospital mortality in critically ill patients [26,27]. Providing patients with ECMO support may help to better evaluate the influence of prolonged infusion or high-dosage regimen on clinical outcomes in critically ill patients.

The PK profile of meropenem in our study was well described by a two-compartment model. Model-predicted typical values of $\mathrm{CL}$ and steady-state volume of distribution $\left(\mathrm{V}_{\mathrm{SS}}=\mathrm{V}_{\mathrm{C}}+\mathrm{V}_{\mathrm{P}}\right)$ for meropenem were $6.37 \mathrm{~L} / \mathrm{h}$ and $17.0 \mathrm{~L}$, respectively. These values were consistent with the results of previous population PK studies including patients with mild to severe renal impairment (CL, 2.0-7.7 L/h; $\left.\mathrm{V}_{\mathrm{SS}} 14.2-26.7 \mathrm{~L}\right)[28,29]$ or patients on ECMO (CL, 2.79-14.7 L/h; $\mathrm{V}_{\mathrm{SS}}, 15.3-33.6 \mathrm{~L}$ ) [10-12]. The mean (s.d.) CL and $\mathrm{V}_{\mathrm{SS}}$ of individual estimates for patients without ECMO support were $5.90(3.60) \mathrm{L} / \mathrm{h}$ and 17.8 (5.47) L, respectively, while those for patients on ECMO support were $6.55(2.14) \mathrm{L} / \mathrm{h}$ and $17.0(2.70) \mathrm{L}$, respectively. There were no differences between the two groups when independent $t$-tests for CL $(p=0.5782)$ and $\mathrm{V}_{\mathrm{SS}}(p=0.6140)$ were performed after the Shapiro-Wilk normality test, which was consistent with the results of three population PK studies involving ECMO patients that found no effect of ECMO on meropenem PK [10-12]. In these three studies, which included 10 to 14 patients on ECMO, the presence or absence of ECMO was not selected as a covariate affecting PK parameters, and ECMO factors such as VA/VV types, flow rate, or pump speed were not included as covariates in the pharmacokinetic model [10-12]. Shekar et al. compared the results of a population PK analysis of $11 \mathrm{ECMO}$ patients with previously published data from 10 non-ECMO patients and found that ECMO patients demonstrated reduced meropenem CL and an increased $V_{S S}$ when compared with controls, but these changes were not statistically significant [10]. Gijsen et al. compared 14 ECMO patients with 11 non-ECMO patients in one study and found no PK alteration by ECMO use [12]. We believe that variations in meropenem PK among critically ill patients of different races, regardless of ECMO support, are limited because the renal clearance of meropenem is largely dependent on the passive process of glomerular filtration [30-32]. 
We tested the effect of renal function on meropenem clearance. When renal function was estimated using Cockcroft-Gault (CG), Modification of Diet in Renal Disease (MDRD), modified MDRD, CKD-EPI, and CKD-EPI equations on the basic PK model, the OFV decreased by $24.512,24.948,22.202,27.933$, and 24.270 , respectively. Therefore, the eGFR estimated using the CKD-EPI equation was considered the best covariate explaining the individual variation in CL. In previous population PK studies of meropenem, renal function calculated by CG equation [10,11,28,33-35], CKD-EPI formula [12], or MDRD [29,36] formula was selected as a covariate affecting CL. The difference in the reduction of OFV was not substantial in our study; there would have been no significant differences in the predictive performance of the model even if other formulas for renal function were used. In our study, only GFR estimated by the CKD-EPI equation was included as a covariate affecting CL, while a recently developed model included body weight and eGFR as covariates [12]. However, since the coefficients of body weight were fixed, only eGFR was the covariate selected by the modeling process.

The predictive performance of the final PK model was evaluated using an external validation dataset. Predictive errors of $203 \%$ and $564 \%$ were observed in two patients. The two samples were collected immediately prior to dosing but were recorded as being collected after initiating dosing; it was more likely to be an error in the documentation than an error in the conduct of the clinical trial. However, since the exact cause could not be identified, we analyzed all data and had poor predictive performance. When the two subjects were excluded, rBias and rRMSE decreased from $17.5 \%$ to $1.59 \%$ and from $91.5 \%$ to $29.4 \%$, respectively, showing that our model has good predictive ability. The range of rBias and rRMSE of the tobramycin model that showed good performance ranged from $4.9 \%$ to $29.4 \%$ and from $47.8 \%$ to $66.9 \%$, respectively [37].

Our study has some limitations. First, the number of patients on ECMO support $(n=8)$ was too small to accurately detect the effect of ECMO on meropenem PK parameters, although the total number of patients $(n=26)$ was sufficient to construct a population PK model. Given the physicochemical properties of meropenem, ECMO therapy may not significantly affect its PK. Second, only one covariate was included in the final PK model; hence, it is difficult to directly use this model for personalized treatments of patients. It is necessary to improve the model through follow-up studies. Third, the predictive performance of the final PK model for 26 patients was not good. The number of blood samples used for external validation was small and substantially affected by two extreme values. However, our model could accurately predict most meropenem concentrations for validation. Fourth, we did not validate our results of PK/PD analysis by evaluating clinical outcomes. Despite these limitations, our study is valuable because it is, to the best of our knowledge, the first population PK analysis of meropenem using model-based simulations in critically ill Korean patients, including those on ECMO support. We believe that the present study has important clinical implications for future research to develop the optimal dose recommendation for such important populations.

\section{Conclusions}

Our model shows that ECMO use does not affect meropenem PK in critically ill patients. Our simulation results suggest that the current dosing regimen of meropenem using i.v. infusion over $30 \mathrm{~min}$ may be related to a suboptimal concentration for empirical treatment in ICU. Therefore, prolonged i.v. infusion over $3 \mathrm{~h}$ or a high-dosage regimen of $2 \mathrm{~g}$ every $8 \mathrm{~h}$ should be considered, particularly at MIC $>2 \mathrm{mg} / \mathrm{L}$ or in patients with augmented renal clearance. Further studies are warranted to validate our model-based regimen, such as assessing the clinical outcomes and evaluating the influence of TDM on clinical outcomes in critically ill patients, including those on ECMO support. 
Supplementary Materials: The following are available online at https://www.mdpi.com/article/10 .3390 / pharmaceutics13111861/s1, Figure S1: Individual fit plots. Closed circle, observed concentration; solid line, individual-predicted concentrations; dotted line, population-predicted concentrations, Figure S2: Relative prediction errors vs observations for the final population pharmacokinetic model of meropenem: (a) plots for all subjects $(n=26),(b)$ plots excluding the two patients with extreme values $(n=24)$.

Author Contributions: Conceptualization and methodology, D.-H.L., H.-S.K. and Y.-K.K.; Data curation, H.-S.K., S.P., H.-i.K., S.-H.L. and Y.-K.K.; Writing-Original draft preparation and formal analysis, D.-H.L., H.-S.K. and Y.-K.K.; Writing-Review and editing, D.-H.L., H.-S.K. and Y.-K.K. All authors have read and agreed to the published version of the manuscript.

Funding: This research was funded by the National Research Foundation of Korea (NRF), the Korea government Ministry of Science and ICT (MSIT) (grant number: NRF-2019R1F1A1062319).

Institutional Review Board Statement: The study protocol was reviewed and approved by the Institutional Review Board of the Hallym University Sacred Heart Hospital (approval cod: IRB No. 2019-05-034, approval date: 08 August 2020) and performed in agreement with the Declaration of Helsinki and Good Clinical Practice. A written informed consent form was signed by each patient or each patient's legally authorized representative before enrollment.

Informed Consent Statement: Informed consent was obtained from all subjects or subject's legally authorized representative.

Data Availability Statement: The datasets generated and/or analyzed during the current study are available from the corresponding author on reasonable request.

Conflicts of Interest: All authors declare no conflict of interest.

\section{References}

1. Roberts, J.A.; Abdul-Aziz, M.H.; Lipman, J.; Mouton, J.W.; Vinks, A.A.; Felton, T.W.; Hope, W.W.; Farkas, A.; Neely, M.N.; Schentag, J.J.; et al. International society of anti-infective pharmacology and the pharmacokinetics and pharmacodynamics study group of the European Society of Clinical Microbiology and infectious diseases. Individualised antibiotic dosing for patients who are critically ill: Challenges and potential solutions. Lancet Infect. Dis. 2014, 14, 498-509. [PubMed]

2. Blot, S.I.; Pea, F.; Lipman, J. The effect of pathophysiology on pharmacokinetics in the critically ill patient-Concepts appraised by the example of antimicrobial agents. Adv. Drug Deliv. Rev. 2014, 77, 3-11. [CrossRef] [PubMed]

3. Goncalves-Pereira, J.; Povoa, P. Antibiotics in critically ill patients: A systematic review of the pharmacokinetics of $\beta$-lactams. Crit. Care 2011, 15, R206. [CrossRef] [PubMed]

4. Mouton, J.W.; van den Anker, J.N. Meropenem clinical pharmacokinetics. Clin. Pharmacokinet. 1995, 28, 275-286. [CrossRef]

5. Baldwin, C.M.; Lyseng-Williamson, K.A.; Keam, S.J. Meropenem: A review of its use in the treatment of serious bacterial infections. Drugs 2008, 68, 803-838. [CrossRef] [PubMed]

6. De Rosa, F.G.; Corcione, S.; Pagani, N.; Stella, M.L.; Urbino, R.; Di Perri, G.; Raschke, R.A. High rate of respiratory MDR gram-negative bacteria in H1N1-ARDS treated with ECMO. Intensive Care Med. 2013, 39, 1880-1881. [CrossRef]

7. Aubron, C.; Cheng, A.C.; Pilcher, D.; Leong, T.; Magrin, G.; Cooper, D.J.; Scheinkestel, C.D.; Pellegrino, V. Infections acquired by adults who receive extracorporeal membrane oxygenation: Risk factors and outcome. Infect. Control Hosp. Epidemiol. 2013, 34, 24-30. [CrossRef]

8. Shekar, K.; Fraser, J.F.; Smith, M.T.; Roberts, J.A. Pharmacokinetic changes in patients receiving extracorporeal membrane oxygenation. J. Crit. Care 2012, 27, 741.e9-741.e18. [CrossRef]

9. Ha, M.A.; Sieg, A.C. Evaluation of altered drug pharmacokinetics in critically ill adults receiving extracorporeal membrane oxygenation. Pharmacotherapy 2017, 32, 221-235. [CrossRef] [PubMed]

10. Shekar, K.; Fraser, J.F.; Taccone, F.S.; Welch, S.; Wallis, S.C.; Mullany, D.V.; Lipman, J.; Roberts, J.A.; ASAP ECMO Study Investigators. The combined effects of extracorporeal membrane oxygenation and renal replacement therapy on meropenem pharmacokinetics: A matched cohort study. Crit. Care 2014, 18, 565. [CrossRef]

11. Hanberg, P.; Obrink-Hansen, K.; Thorsted, A.; Bue, M.; Tottrup, M.; Friberg, L.E.; Hardlei, T.F.; Søballe, K.; Gjedsted, J. Population pharmacokinetics of meropenem in plasma and subcutis from patients on extracorporeal membrane oxygenation treatment. Antimicrob. Agents Chemother. 2018, 62, e02390-17. [CrossRef] [PubMed]

12. Gijsen, M.; Dreesen, E.; Annaert, P.; Nicolai, J.; Debaveye, Y.; Wauters, J.; Spriet, I. Meropenem pharmacokinetics and target attainment in critically ill patients are not affected by extracorporeal membrane oxygenation: A matched cohort analysis. Microorganisms 2021, 9, 1310. [CrossRef]

13. Dosne, A.G.; Bergstrand, M.; Karlsson, M.O. A strategy for residual error modeling incorporating scedasticity of variance and distribution shape. J. Pharmacokinet. Pharmacodyn. 2016, 43, 137-151. [CrossRef] [PubMed] 
14. Pea, F.; Della Siega, P.; Cojutti, P.; Sartor, A.; Crapis, M.; Scarparo, C.; Bassetti, M. Might real-time pharmacokinetic/pharmacodynamic optimisation of high-dose continuous-infusion meropenem improve clinical cure in infections caused by KPC-producing Klebsiella pneumoniae? Int. J. Antimicrob. Agents 2017, 49, 255-258. [CrossRef]

15. Heil, E.L.; Nicolau, D.P.; Farkas, A.; Roberts, J.A.; Thom, K.A. Pharmacodynamic target attainment for cefepime, meropenem, and piperacillin-tazobactam using a pharmacokinetic/pharmacodynamic-based dosing calculator in critically ill patients. Antimicrob. Agents Chemother. 2018, 62, e01008-18. [CrossRef] [PubMed]

16. Liebchen, U.; Klose, M.; Paal, M.; Vogeser, M.; Zoller, M.; Schroeder, I.; Schmitt, L.; Huisinga, W.; Michelet, R.; Zander, J.; et al. Evaluation of the MeroRisk calculator, a use-friendly tool to predict the risk of meropenem target non-attainment in critically ill patients. Antibiotics 2021, 10, 468. [CrossRef] [PubMed]

17. Kühn, D.; Metz, C.; Seiler, F.; Wehrfritz, H.; Roth, S.; Alqudrah, M.; Becker, A.; Bracht, H.; Wagenpfeil, S.; Hoffmann, M.; et al. Antibiotic therapeutic drug monitoring in intensive care patients treated with different modalities of extracorporeal membrane oxygenation (ECMO) and renal replacement therapy: A prospective, observational single-center study. Crit. Care 2020, $24,664$. [CrossRef]

18. Patel, T.S.; Nagel, J.L. Clinical outcomes of Enterobacteriaceae infections stratified by carbapenem MICs. J. Clin. Microbiol. 2015, 53, 201-205. [CrossRef]

19. Esterly, J.S.; Wagner, J.; McLaughlin, M.M.; Postelnick, M.J.; Qi, C.; Scheetz, M.H. Evaluation of clinical outcomes in patients with bloodstream infections due to Gram-negative bacteria according to carbapenem MIC stratification. Antimicrob. Agents Chemother. 2012, 56, 4885-4890. [CrossRef] [PubMed]

20. O’Donnell, J.N.; Rhodes, N.J.; Biehle, L.R.; Esterly, J.S.; Patel, T.S.; McLaughlin, M.M.; Hirsch, E.B. Assessment of mortality stratified by meropenem minimum inhibitory concentration in patients with Enterobacteriaceae bacteremia: A patient-level analysis of published data. Int. J. Antimicrob. Agents 2020, 55, 105849. [CrossRef]

21. De Waele, J.J.; Akova, M.; Antonelli, M.; Canton, R.; Carlet, J.; De Backer, D.; Dimopoulos, G.; Garnacho-Montero, J.; Kesecioglu, J.; Lipman, J.; et al. Antimicrobial resistance and antibiotic stewardship programs in the ICU: Insistence and persistence in the fight against resistance. A position statement from ESICM/ESCMID/WAAAR round table on multi-drug resistance. Intensive Care Med. 2018, 44, 189-196. [CrossRef] [PubMed]

22. Sjövall, F.; Alobaid, A.S.; Wallis, S.C.; Perner, A.; Lipman, J.; Roberts, J.A. Maximally effective dosing regimens of meropenem in patients with septic shock. J. Antimicrob. Chemother. 2018, 73, 191-198. [CrossRef] [PubMed]

23. Lertwattanachai, T.; Montakantikul, P.; Tangsujaritvijit, V.; Sanguanwit, P.; Sueajai, J.; Auparakkitanon, S.; Dilokpattanamongkol, P. Clinical outcomes of empirical high-dose meropenem in critically ill patients with sepsis and septic shock: A randomized controlled trial. J. Intensive Care 2020, 8, 26. [CrossRef]

24. Kothekar, A.T.; Divatia, J.V.; Myatra, S.N.; Patil, A.; Krishnamurthy, M.N.; Maheshwarappa, H.M.; Siddiqui, S.S.; Gurjar, M.; Biswas, S.; Gota, V. Clinical pharmacokinetics of 3-h extended infusion of meropenem in adult patients with severe sepsis and septic shock: Implications for empirical therapy against Gram-negative bacteria. Ann. Intensive Care 2020, 10, 4. [CrossRef] [PubMed]

25. Eisert, A.; Lanckohr, C.; Frey, J.; Frey, O.; Wicha, S.G.; Horn, D.; Ellger, B.; Schuerholzi, T.; Marx, G.; Simond, T.-P. Comparison of two empirical prolonged infusion dosing regimens for meropenem in patients with septic shock: A two-center pilot study. Int. J. Antimicrob. Agents 2021, 57, 106289. [CrossRef] [PubMed]

26. Ahmed, N.; Jen, S.P.; Altshuler, D.; Papadopoulos, J.; Pham, V.P.; Dubrovskaya, Y. Evaluation of meropenem extended versus intermittent infusion dosing protocol in critically ill patients. J. Intensive Care Med. 2020, 35, 763-771. [CrossRef]

27. Roberts, J.A.; Abdul-Aziz, M.H.; Davis, J.S.; Dulhunty, J.M.; Cotta, M.O.; Myburgh, J.; Bellomo, R.; Lipman, J. Continuous versus intermittent beta-lactam infusion in severe sepsis. A meta-analysis of individual patient data from randomized trials. Am. J. Respir. Crit. Care Med. 2016, 194, 681-691. [CrossRef] [PubMed]

28. Roberts, J.A.; Kirkpatrick, C.M.; Roberts, M.S.; Robertson, T.A.; Dalley, A.J.; Lipman, J. Meropenem dosing in critically ill patients with sepsis and without renal dysfunction: Intermittent bolus versus continuous administration? Monte Carlo dosing simulations and subcutaneous tissue distribution. J. Antimicrob. Chemother. 2009, 64, 142-150. [CrossRef]

29. Jaruratanasirikul, S.; Thengyai, S.; Wongpoowarak, W.; Wattanavijitkul, T.; Tangkitwanitjaroen, K.; Sukarnjanaset, W.; Jullangkoon, M.; Samaeng, M. Population pharmacokinetics and Monte Carlo dosing simulations of meropenem during the early phase of severe sepsis and septic shock in critically ill patients in intensive care units. Antimicrob. Agents Chemother. 2015, 59, $2995-3001$. [CrossRef]

30. Kim, Y.K.; Lee, D.H.; Jeon, J.; Jang, H.J.; Kim, H.K.; Jin, K.; Lim, S.-N.; Lee, S.S.; Park, B.S.; Kim, W.; et al. Population pharmacokinetic analysis of meropenem after intravenous infusion in Korean patients with acute infections. Clin. Ther. 2018, 40, 1384-1395. [CrossRef]

31. Tsai, D.; Jamal, J.A.; Davis, J.S.; Lipman, J.; Roberts, J.A. Interethnic differences in pharmacokinetics of antibacterials. Clin. Pharmacokinet. 2015, 54, 243-260. [CrossRef]

32. Kim, K.; Johnson, J.A.; Derendorf, H. Differences in drug pharmacokinetics between East Asians and Caucasians and the role of genetic polymorphisms. J. Clin. Pharmacol. 2004, 44, 1083-1105. [CrossRef]

33. Isla, A.; Rodriguez-Gascon, A.; Troconiz, I.F.; Bueno, L.; Solinis, M.A.; Maynar, J.; Izquierdo, J.A.; Pedraz, J.L. Population pharmacokinetics of meropenem in critically ill patients undergoing continuous renal replacement therapy. Clin. Pharmacokinet. 2008, 47, 173-180. [CrossRef] [PubMed] 
34. Chung, E.K.; Cheatham, S.C.; Fleming, M.R.; Healy, D.P.; Kays, M.B. Population pharmacokinetics and pharmacodynamics of meropenem in nonobese, obese, and morbidly obese patients. J. Clin. Pharmacol. 2017, 57, 356-368. [CrossRef]

35. Ehmann, L.; Zoller, M.; Minichmayr, I.K.; Scharf, C.; Huisinga, W.; Zander, J.; Kloft, C. Development of a dosing algorithm for meropenem in critically ill patients based on a population pharmacokinetic/pharmacodynamic analysis. Int. J. Antimicrob. Agents 2019, 54, 309-317. [CrossRef] [PubMed]

36. Frippiat, F.; Musuamba, F.T.; Seidel, L.; Albert, A.; Denooz, R.; Charlier, C.; Van Bambeke, F.; Wallemacq, P.; Descy, J.; Lambermont, B.; et al. Modelled target attainment after meropenem infusion in patients with severe nosocomial pneumonia: The PROMESSE study. J. Antimicrob. Chemother. 2015, 70, 207-216. [CrossRef] [PubMed]

37. Bloomfield, C.; Staatz, C.E.; Unwin, S.; Hennig, S. Assessing predictive performance of published population pharmacokinetic models of intravenous tobramycin in pediatric patients. Antimicrob. Agents Chemother. 2016, 60, 3407-3414. [CrossRef] 